\title{
PARTICULATE BEHAVIOR IN A CONTROLLED-PROFILE PULVERIZED COAL-FIRED REACTOR: A STUDY OF COUPLED TURBULENT PARTICLE DISPERSION AND THERMAL RADIATION TRANSPORT
}

\author{
Quarterly Technical Progress Report \\ For Period June 15, 1995 to September 14, 1995
}

Mardson Queiroz and Brent W. Webb

Brigham Young University

Provo, UT 84602

\section{Prepared for the United States Department of Energy \\ Pittsburgh Energy Technology Center (PETC)}

Under Contract No. DE-FG22-91PC91308

"US/DOE Patent Clearance is not required prior to the publication of this document"

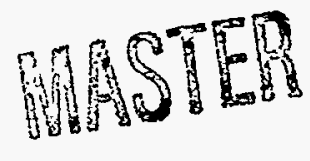

DISTRIBUTION OF ThIS DOCUMENT IS UNLIMITED 


\section{DISCLAIMER}

This report was prepared as an account of work sponsored by the United States Government. Neither the United States nor the United States Department of Energy, nor any of their employees nor any of their contractors, subcontractors, or their employees, makes any warranty, expressed or implied, or assumes any legal liability or responsibility for the accuracy, completeness, or usefulness of any information, apparatus, product or process disclosed, or represents that its use would infringe privately owned rights.

\section{DISCLAMMER}

This report was prepared as an account of work sponsored by an agency of the United States Government. Neither the United States Government nor any agency thereof, nor any of their employees, makes any warranty, express or implied, or assumes any legal liability or responsibility for the accuracy, completeness, or usefulness of any information, apparatus, product, or process disclosed, or represents that its use would not infringe privately owned rights. Reference herein to any specific commercial product, process, or service by trade name, trademark, manufacturer, or otherwise does not necessarily constitute or imply its endorsement, recommendation, or favoring by the United States Government or any agency thereof. The views and opinions of authors expressed herein do not necessarily state or reflect those of the United States Government or any agency thereof. 


\section{FORWARD}

This report summarizes technical progress during the sixteenth quarter (June 15, 1995 to September 14, 1995) of a three-year study conducted for the Department of Energy (DOE) under contract number DE-FG22-91PC91308. The principal investigators for this work are Dr. Mardson Queiroz and Dr. Brent W. Webb; Dr. Clifford Smith is the technical representative for DOE. 


\section{TABLE OF CONTENTS}

PAGE

DISCLAIMER

FORWARD

ABSTRACT IV IV

1. OBJECTIVES AND SCOPE 1

$\begin{array}{lll}1.1 & \text { BACKGROUND } & 1\end{array}$

$\begin{array}{lll}1.2 & \text { OBJECTIVES } & 1\end{array}$

$\begin{array}{ll}1.3 \\ \text { TECHNICAL APPROACH } & 1\end{array}$

2. SUMMARY OF TECHNICAL PROGRESS 2

2.1 Multiple-Time Scale Model for Turbulent Swirling Flows 2

2.2 Convective-Radiative Heat Transfer Partitioning 2

3. REFERENCES 4

4. APPENDIX 


\section{ABSTRACT}

During the sixteenth quarter progress has been made in the area of turbulence modeling and in data reduction of heat flux measurements. A multiple-time-scale turbulence model was developed for axisymmetric, swirling flows. 


\section{OBJECTIVES AND SCOPE}

\subsection{BACKGROUND}

Improved understanding of the fundamental processes involved in pulverized-coal combustion is needed to make the energy extraction more efficient and the combustion byproducts environmentally safe. While the characterization of the local particulate behavior (concentration, size, and velocity) is important to the understanding of virtually all processes in a pulverized coal-fired furnace, it influences in a more direct way the turbulent particle dispersion and thermal radiation heat transfer. Yet the local particulate dynamics have gone relatively unaddressed, primarily because of lack of adequate instrumentation to carry out such a study. With recent advances in optical techniques such an effort is now possible. This proposal seeks to characterize the local particulate concentration, velocity, and size distribution in a wellcontrolled, parametrically-varied laboratory-scale reactor using a new laser diagnostic technique. This newly-developed technique is the only one currently available for the investigation of aspherical particles. The particulate data will be collected simultaneously with local gas temperature and wall radiant heat flux distributions.

\subsection{OBJECTIVES}

This report describes recent progress in a fundamental, three-year investigation of the coupled problem of turbulent particle dispersion and thermal radiation transport. The project's objective is to make measurements of particle size, velocity, number density, temperature and wall radiant heat flux in a parametrically-controlled reactor presently existent at Brigham Young University (BYU). Although the study proposed here is primarily designed to provide experimental data not currently available for the evaluation of turbulent particle dispersion and radiation models, comparisons of analytical predictions and the experimental data obtained will be performed, using appropriate submodels integral to comprehensive pulverized-coal combustion codes existent at BYU.

\subsection{TECHNICAL APPROACH}

To accomplish the above objectives, the project is divided in the following tasks:

- Design and fabrication of a modified section for the BYU controlled-profile reactor, which will allow access of several probes to be used in the proposed study.

- Design and fabrication of a two-color pyrometer and cooled probe for local particulate temperature measurement.

- Characterization of the non-reacting turbulent flow field in the reactor using the PCSV-P probe, which will serve as an input during the turbulent particle dispersion submodel validation.

- Literature review dealing with particle dispersion and radiation transport in support of the model validation effort.

- Perform the parametrically-controlled measurements in the controlled-profile reactor.

- Experimental data analysis.

- A comprehensive comparison of experimental data and model predictions.

- Final report. 


\section{SUMMARY OF TECHNICAL PROGRESS}

\subsection{Multiple-Time Scale Model for Turbulent Swirling Flows}

The standard $k-\varepsilon$ model is single-time scale turbulence model, i.e., only one time scale is used to describe both the turbulent transport of mass and momentum and the dissipation of the turbulent kinetic energy. As a result of this their predictive capability degenerates rapidly for complex flow situations such as the case of swirling flows (Kim, 1991). Swirl burners are normally used in combustion systems such as pulverized coal reactors. This is because swirling flows facilitate flame stabilization and good mixing between fuel and oxidizer. Hence in comprehensive coal combustion codes it is necessary to have a turbulence model which is capable of accurately predicting swirling flows. For this reason a Multiple-TimeScale (MTS) turbulence model which accounts for generation, cascade and dissipation of turbulent kinetic energy was developed. This model was incorporated into the 1974 Imperial College TEACH (teaching elliptic axisymmetric characteristics heuristically) computer program (Gosman \& Ideriah, 1974). The TEACH code was also modified to account for swirling flows. This was done by adding a subroutine for solving the azimuthal momentum equation with appropriate wall functions for boundary conditions. Also the source term for the radial momentum equation was modified to account for the effect of swirl. The equations for swirling flows can be found in Lilley and Rhode (1982).

The MTS model developed here is same as the one proposed by Kim and Chen (1989) and is based on simplified split-spectrum method. In this turbulence model the turbulence field is described by four partial differential equations for turbulent kinetic energy of large eddies $\left(k_{p}\right)$, the turbulent kinetic energy of fine-scale eddies $\left(k_{t}\right)$, the energy transfer rate $\left(\varepsilon_{p}\right)$, and the dissipation rate $\left(\varepsilon_{\ell}\right)$. It has been shown by Kim and Chen (1989) that this MTS model yields significantly improved computational results as compared to the standard $k-\varepsilon$ model for a number of complex flows including swirling flows. The MTS model developed was studied for the case of backward facing step (Kim et al., 1980) and coaxial swirling jets (Roback \& Johnson, 1983). Figure 1 (a) and (b) illustrates the velocity vectors for the case of backward-facing step using standard $k-\varepsilon$ and MTS model respectively. For a grid of $75 \times 50$ using an expansion factor of 1.05 for the axial grid cells the calculated reattachment using the MTS model was $7.62 \mathrm{H}$, where $H$ is the step height $(0.0381$ meters). This value is almost identical to the experimentally observed value of $7.6 \mathrm{H}$ (Avva et al., 1988). For the same grid the standard $k-\varepsilon$ turbulence model give the reattachment length to be $5.48 \mathrm{H}$.

\subsection{Convective-Radiatiave Heat Transfer Partitioning}

From the total and radiative heat flux measurements the convective heat flux to the reactor walls was calculated. These calculations were determined using a data reduction scheme developed by Butler (1992). The convective heat flux to the probe is equal to the difference of the total and radiative fluxes measured by the probes. Using this value and the local wall and gas temperatures a convective heat transfer coefficient can be calculated. This coefficient corresponds to the convective heat transfer between the reactor gasses and the probe and is temperature dependent. In order to use it for convective heat transfer to the walls it has to be adjusted by the ratio to the $4 / 10$ ths power of the average temperature of the probe and the combustion gasses divided by the average temperature of the wall and the combustion gasses. This convective heat transfer coefficient can then be used to calculate the convective heat transfer to the walls which is the new coefficient times the temperature difference between the combustion gasses and the walls. The radiative heat flux plus the convective heat flux to the walls is the total heat flux to the walls. 
The measurements of the total, convective and radiative heat flux in the reactor are shown in Fig. 2. Data shown are representative of multiple measurements made throughout the testing periods. The graph of total heat flux shows the combined convective and radiative transfer to the probe. A constant total heat flux for the top three ports is followed by a smooth decay as axial distance from the quarl increases. The radiative measurements show a constant decay of radiative heat flux with increased separation distance from the quarl. These measurements make sense in light of other measurements and visual observations. The convective part of the total heat flux is a function of the gas velocity and the temperature difference between the gas and the probe. Near the wall, where the measurements were taken, the gas temperature reaches a maximum at the third port. The flow field at this point provides high velocities to enhance heat transfer. Therefore, the convective heat flux reaches a maximum at this port and then decreases as the gas temperature decreases. The radiative heat flux is independent of the gas temperature. It is only affected by the particle and wall temperatures. At the top port the reaction zone is in direct line with the probe. The reaction is so intense that the medium is optically thick in the visible and the probe is effectively shielded from the far wall of the reactor. Therefore, it only measures heat flux from the hot reaction zone. At the lower ports the reaction zone is not optically thick, causing most of the incident radiative flux to come from the reactor walls. Since the reactor walls decrease in temperature with increased distance from the quarl, the radiative flux to the walls also decreases. The flat zone of almost constant total heat flux in the top three ports is a result of the above mentioned observations. The convective heat transfer increases in the top three ports are offset by the decreases in the radiative heat transfer. Below port 3 , the lack of reaction and the cooler wall temperature causes an overall decrease in heat flux to both probes.

The heat flux to which the wall is exposed is different than the heat flux to which the probe is exposed. The probe temperature is kept near $30^{\circ} \mathrm{C}$, while the average wall temperature varies linearly from $1300 \mathrm{~K}$ at the top of the reactor to $1100 \mathrm{~K}$ at the bottom of the reactor. The change in temperature gives rise to a large difference in the magnitude of the convective heat flux to the wall and to the probe. This can be seen by the difference between the line showing total heat flux to the probe and total heat flux to the wall. In the top of the reactor the wall temperature was hotter than the gas temperature causing convective heat transfer from the walls to the gas. This shows up as negative convective heat transfer to the walls. As can be seen in Fig. 2, the total heat flux to the walls is almost identical to the radiative heat flux. This indicates that heat transfer within the reactor is dominated by radiation. 


\section{LIST OF FIGURES}

Figure 1. Velocity vector plot for the problem of turbulent backward facing step with step height of 0.0381 meters: (a) using standard $k-\varepsilon$ model and (b) using MTS model.

Figure 2. Radiation, convection, and total heat flux measurements as a function of axial position in the reactor.

\section{REFERENCES}

Avva, R.K., Kline, S.J. and Ferziger, J.H. (1988). Computation of the Turbulent Flow Over A Backward-Facing Step Using the Zonal Modeling Approach. TF-33, Thermosciences Division, Department of Mechanical Engineering, Stanford University.

Butler, B. (1992). An Experimental Evaluation of Radiant Energy Transport in Particle Laden - Flames, Ph.D. Dissertation, Brigham Young University, Provo, Utah.

Gosman, A.D. and Ideriah, F.J.K. (1976). TEACH-2E: A General Computer Program for TwoDimensional, Turbulent, Recirculating Flows. Report, Department of Mechanical Engineering, Imperial College, London.

Kim, S.W. (1991). Calculation of Divergent Channel Flows with a Multiple-Time-Scale Turbulence Model. AIAA Journal, vol. 29, no. 4, pp. 547-554.

Kim, S.W. and Chen, C.P. (1989). A Multiple-Time-Scale Turbulence Model Based On Variable Partitioning Of The Turbulent Kinetic Energy Spectrum. Numerical Heat Transfer, Part B, vol. 16, pp. 193-211.

Kim, J., Kline, S.J. and Johnston J.P. (1980). Investigation of a Reattaching Turbulent Shear Layer: Flow over a Backward-Facing Step. J. Fluids Eng., vol. 102, pp. 302-308.

Lilley D.G. and Rhode D.L. (1982). A Computer Code for Swirling Turbulent Axisymmetric Recirculating Flows in Practical Isothermal Combustor Geometries. NASA CR-3442.

Roback, R. and Johnson, B.V. (1983). Mass and Momentum Turbulent Transport Experiments with Confined Swirling Coaxial Jets. NASA CR-168252. 
4. APPENDIX

REPORT DISTRIBUTION LIST

Ms. Marilyn Keane

PM-01, MS 922-206

U.S. Department of Energy

Pittsburgh Energy Technology Center

P.O. Box 10940

Pittsburgh, PA 15236

Ms. Rhonda L. Dupree

AD-22, MS 921-118

U.S. Department of Energy

Pittsburgh Energy Technology Center

P.O. Box 10940

Pittsburgh, PA 15236

Office of Technology Transfer

Attn: Kay Downey

Mail Stop 58-M217

U.S. Department of Energy

Pittsburgh Energy Technology Center

P.O. Box 10940

Pittsburgh, PA 15236

U.S. Department of Energy

Attn: Document Control Center

Mail Stop 921-118

P.O. Box 10940

Pittsburgh, PA 15236-0940

Dr. Clifford Smith

U.S. Department of Energy

Pittsburgh Energy Technology Center

P.O. Box 10940

Pittsburgh, PA 15236 


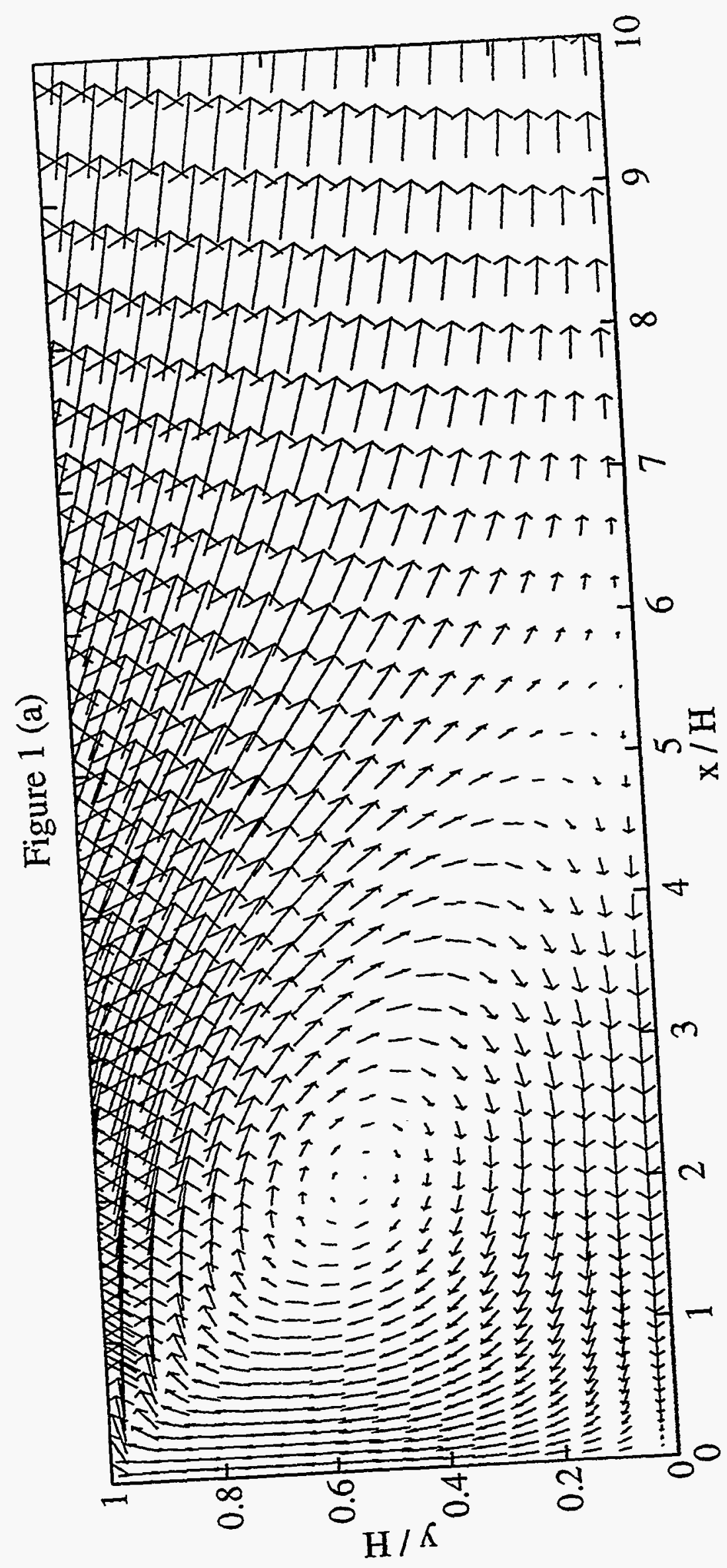




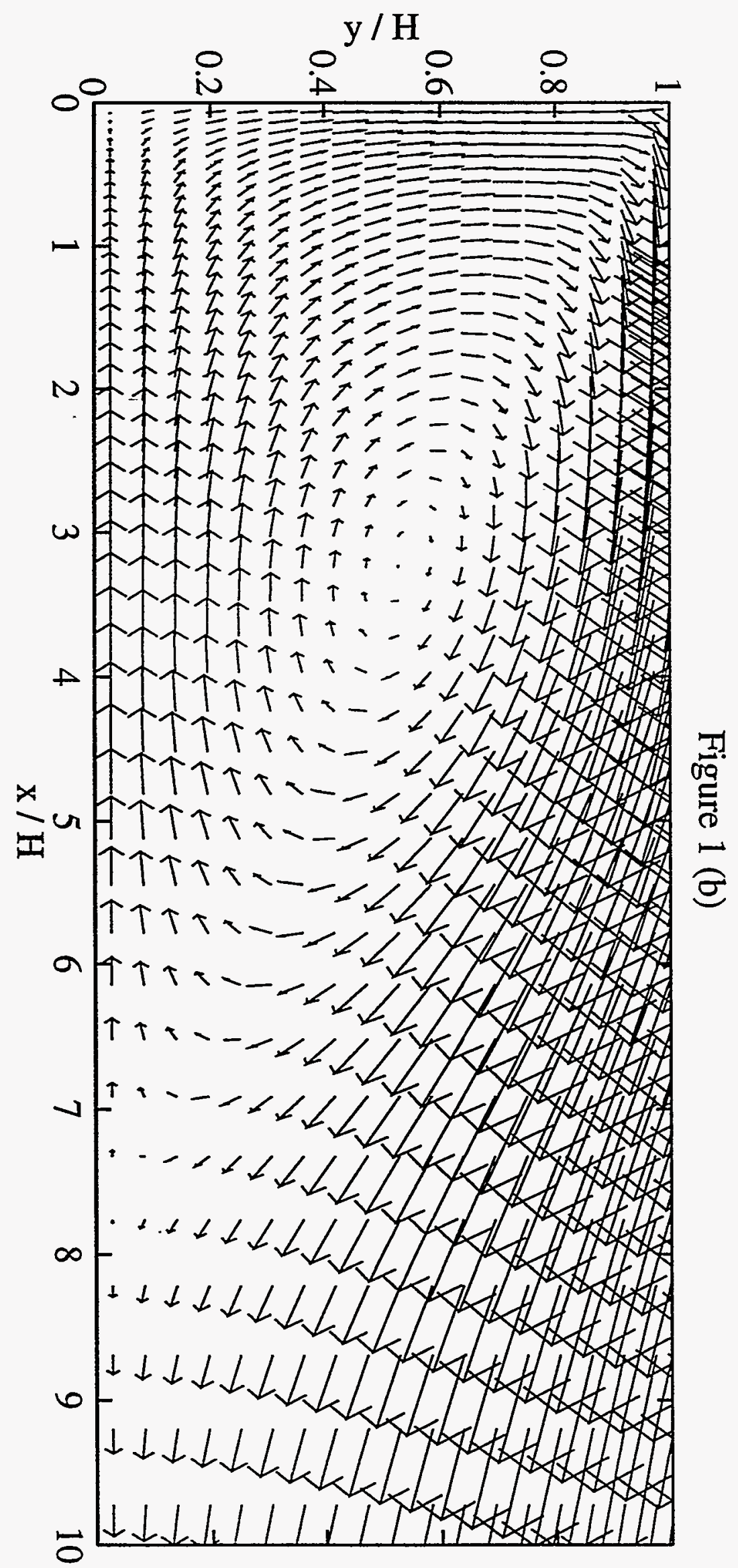


Figure 2

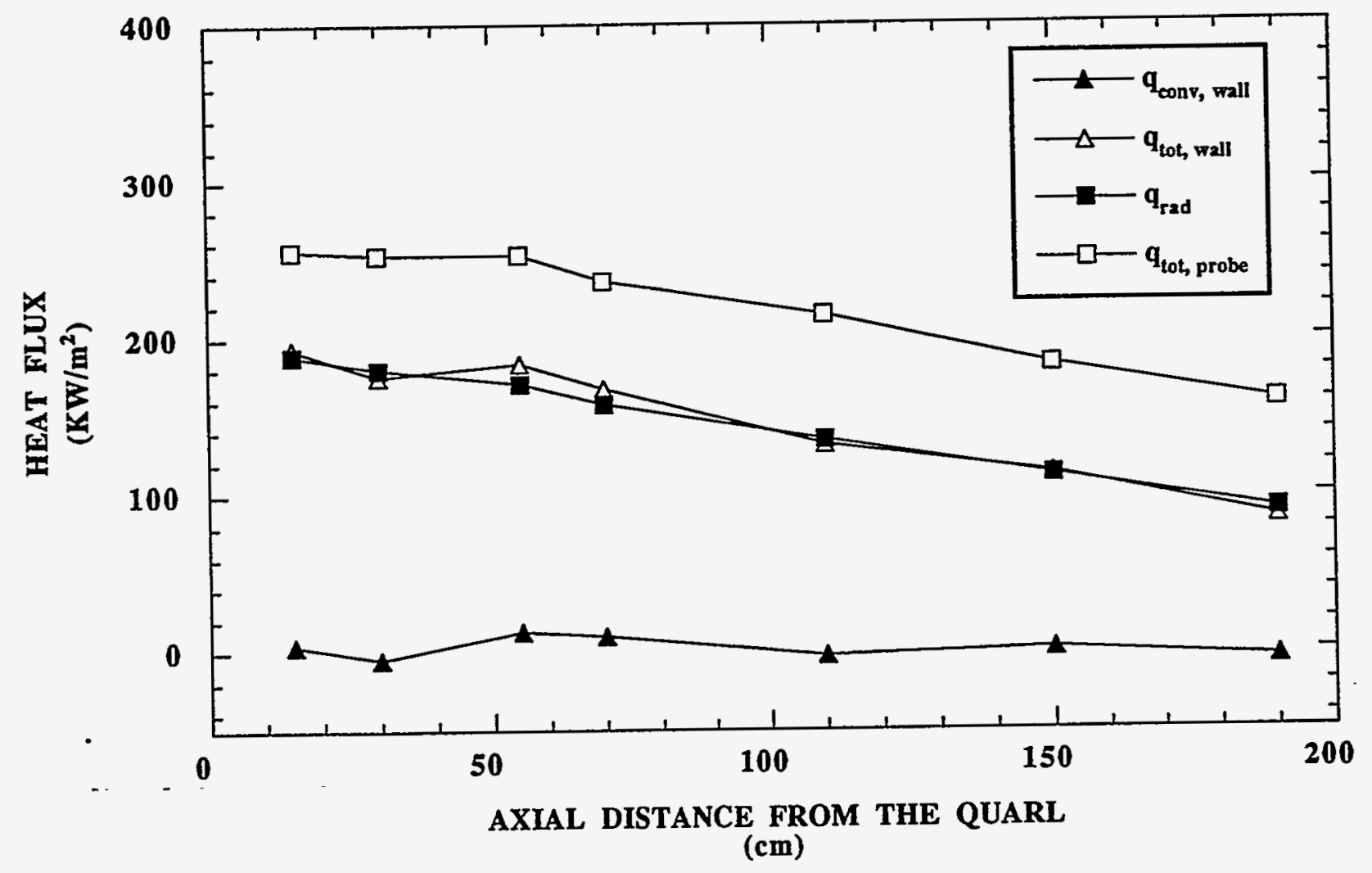

